\title{
Ethnicity and mycobacterial lineage as determinants of tuberculosis disease phenotype
}

\author{
Manish Pareek, ${ }^{1,2,3}$ Jason Evans, ${ }^{4}$ John Innes, ${ }^{5}$ Grace Smith, ${ }^{4}$ Suzie Hingley-Wilson, ${ }^{1}$ \\ Kathryn E Lougheed, ${ }^{6}$ Saranya Sridhar, ${ }^{1}$ Martin Dedicoat, ${ }^{5}$ Peter Hawkey, ${ }^{4,7}$ \\ Ajit Lalvani ${ }^{1}$
}

- Additional data are published online only. To view these files please visit the journal online (http://dx.doi. org/10.1136/thoraxjnl-2012201824).

${ }^{1}$ Tuberculosis Research Unit, National Heart and Lung Institute, Imperial College London, London, UK ${ }^{2}$ Department of Infectious Disease Epidemiology, Imperial College London, London, UK ${ }^{3}$ Department of Infection, Immunity and Inflammation, University of Leicester, Leicester, UK

${ }^{4}$ Health Protection Agency Midlands Laboratory, Heart of England NHS Foundation Trust, Bordesley Green East, Birmingham, UK

${ }^{5}$ Department of Infection and Tropical Medicine, Heart of England NHS Foundation Trust, Bordesley Green East,

Birmingham, UK

${ }^{6}$ Department of Integrative Cell Biology, Division of Cell \& Molecular Biology, Imperial College London, London, UK ${ }^{7}$ School of Immunity and Infection, The Medical School, University of Birmingham, Edgbaston, Birmingham, UK

\section{Correspondence to}

Prof Ajit Lalvani, Tuberculosis Research Unit, National Heart and Lung Institute, Imperial

College London, London W21PG, UK;

a.lalvani@imperial.ac.uk

Received 27 February 2012 Revised 11 August 2012

Accepted 15 August 2012

Published Online First

27 September 2012

\section{ABSTRACT \\ Background Emerging evidence suggests that Mycobacterium tuberculosis (Mtb) lineage and host ethnicity can determine tuberculosis (TB) clinical disease patterns but their relative importance and interaction are unknown.}

Methods We evaluated prospectively collected TB surveillance and Mtb strain typing data in an ethnically heterogeneous UK population. Lineage assignment was denoted using 15-loci mycobacterial interspersed repetitive units containing variable numbers of tandem repeats (MIRU-VNTR) and MIRU-VNTRplus. Geographical and ethnic associations of the six global Mtb lineages were identified and the influence of lineage and demographic factors on clinical phenotype were assessed using multivariate logistic regression.

Results Data were available for 1070 individuals with active TB which was pulmonary only, extrapulmonary only and concurrent pulmonary-extrapulmonary in $52.1 \%, 36.9 \%$ and $11.0 \%$ respectively. The most prevalent lineages were Euro-American (43.7\%), East African Indian (30.2\%), Indo-Oceanic (13.6\%) and East Asian (12.2\%) and were geo-ethnically restricted with, for example, Indian subcontinent ethnicity inversely associated with Euro-American lineage (OR 0.23; 95\% $\mathrm{Cl} 0.14$ to 0.39 ) and positively associated with the East African-Indian lineage (OR 4.04; 95\% Cl 2.19 to 7.45). Disease phenotype was most strongly associated with ethnicity (OR for extrathoracic disease 21.14 (95\% Cl 6.08 to 73.48) for Indian subcontinent and 14.05 (3.97 to 49.65) for Afro-Caribbean), after adjusting for lineage. With East Asian lineage as the reference category, the Euro-American (OR 0.54; $95 \% \mathrm{Cl} 0.32$ to 0.91 ) and East-African Indian (OR 0.50; $95 \% \mathrm{Cl} 0.29$ to $0.86)$ lineages were negatively associated with extrathoracic disease, compared with pulmonary disease, after adjusting for ethnicity.

Conclusions Ethnicity is a powerful determinant of clinical TB phenotype independently of mycobacterial lineage and the role of ethnicity-associated factors in pathogenesis warrants investigation.

\section{INTRODUCTION}

Worldwide, Mycobacterium tuberculosis (Mtb) continues to cause significant morbidity and mortality with an estimated 8.8 million cases and 1.1 million deaths in 2011. ${ }^{1}$ Genetic strain typing has identified six major lineages of $M t b$ which epidemiologically coassociate with distinct geographical regions. ${ }^{2-5}$ Moreover, lineages can differ in the

\section{Key messages}

What is the key question?

- Mycobacterium tuberculosis (Mtb) presents as a spectrum of disease but the relative importance of mycobacterial lineage and host ethnicity in determining clinical phenotype is unknown.

\section{What is the bottom line?}

- Ethnicity is a powerful determinant of clinical tuberculosis phenotype independently of mycobacterial lineage.

\section{Why read on?}

- This large UK-based study provides the first evidence for the predominance of host ethnicity over mycobacterial lineage in determining clinical disease phenotype and highlights the need to investigate ethnicity-associated factors in the pathogenesis of tuberculosis.

host response that they induce ${ }^{6}$ with, for example, the Beijing (East Asian) lineage inducing lower levels of inflammatory cytokines ${ }^{7} 8$ while exhibiting enhanced intracellular growth. ${ }^{9}$

Although these in vitro differences in host response might be expected to result in the well recognised different clinical phenotypes observed in distinct demographic groups, ${ }^{10-12}$ the impact and influence of different lineages on clinical patterns of active tuberculosis (TB) still remains unclear. A notable exception is the Beijing (East Asian) lineage which, in certain ethnic groups, has been associated with a more aggressive clinical course $^{13}$ and extrapulmonary forms of $\mathrm{TB},{ }^{14-16}$ although other studies have failed to document these associations. ${ }^{17-20}$ More recently, European studies ${ }^{19}{ }^{21}$ have suggested that the Central Asian lineage is associated with extrapulmonary disease whilst two Pakistani ${ }^{22} 23$ studies found the opposite. However, studies conducted to date have, with one recent exception, ${ }^{20}$ mainly examined homogeneous populations where the relative importance of ethnicity, compared with lineage, on disease phenotype was not independently examined.

Given the recognised association of different lineages and ethnic groups, ${ }^{2-5}$ and the known link between extrapulmonary disease and non-white 
ethnic groups, ${ }^{10-12}$ we reasoned that to determine whether lineages influence clinical patterns of disease it would be necessary to dissect out the relative influence of the lineage itself from ethnicity. We therefore prospectively collated data on host demographic factors, clinical patterns of disease and mycobacterial genotype for culture-confirmed cases of TB in a singlecentre UK setting, with a unique ethnic mix, to assess the global phylogeography of the strains in our dataset, identify the demographic factors associated with different lineages and to establish which, if any, factors, including lineage, were associated with distinct clinical patterns of disease.

\section{METHODS}

\section{Study design and data source}

We analysed data from a routine, anonymised, centralised clinical surveillance database maintained as part of usual care for all patients diagnosed with active TB in two closely related metropolitan areas in the UK (Birmingham and Solihull-combined population approximately 1.2 million; ${ }^{24} \mathrm{~TB}$ incidence varies from 9-88 per 100000 population per year ${ }^{25}$ ).

\section{MIRU-VNTR typing}

Since mid-2003 all culture-positive $M t b$ isolates received, and identified, as $M t b$ complex by the Health Protection Agency Midlands Regional Centre for Mycobacteriology have been routinely analysed by 15 -loci mycobacterial interspersed repetitive units containing variable numbers of tandem repeats (MIRU-VNTR) typing (ETR-A, B, C, D, E and MIRU-02, 10, $16,20,23,24,26,27,39,40)$. MIRU-VNTR typing analyses the number of repetitive DNA sequences at multiple independent genetic loci. ${ }^{26} 27$ The values generated are automatically recorded on the clinical surveillance database.

\section{Study population, variables and assignment to lineage}

We included all cases of active TB diagnosed between 1 July 2003 and 28 February 2010 with complete information on age, sex, country of birth (local or foreign born), ethnicity, site of disease and MIRU-VNTR value; patients with missing information for one or more of these variables or culture-negative disease were excluded from analysis.

Information on year of notification, age, sex, local/foreign born, country of birth if foreign born, ethnicity, time since entry (only applies to foreign-born immigrants and calculated as time between arrival in the UK and diagnosis of active TB), employment status, HIV status, previous history of TB, site of disease, specific organs involved, duration of symptoms before treatment commencement, drug sensitivity and MIRU-VNTR value were retrieved from the database.

We used the MIRU-VNTRplus database ${ }^{28}$ (http://www. miru-vntrplus.org/) to assign strains with MIRU-VNTR values to one of six global lineages as defined by Gagneux et $a l^{2}$ : East Asian, Euro-American, East African Indian, Indo-Oceanic, West African-1 and West African-2. Strains which could not be assigned to any lineage and those which were identified as being non $M t b$ (such as Mycobacterium bovis) were excluded from analysis.

Ethnicity was defined in line with the Office for National Statistics classification ${ }^{29}$ (White, Indian subcontinent, Afro-Caribbean, Oriental/Other Asia, Other). We explored the patterns of disease in local-born ethnic groups versus foreignborn ethnic groups by creating a composite variable 'location of birth/ethnicity' with individuals categorised as being local or foreign born non-white ethnicity.
HIV testing of patients diagnosed with active TB is highly inconsistent in the UK and this was reflected by this variable being inconsistently recorded in our dataset. Therefore, we considered patients either as HIV positive (if recorded) or as negative/unknown (for all other individuals).

\section{Definitions of TB phenotypes}

We classified all cases of active TB into the following clinical phenotypes: extrathoracic disease only (only extrapulmonary site(s) outside the thoracic cavity); extrapulmonary only (only one or more extrapulmonary site(s) involved but including pleural $\mathrm{TB}$ and intrathoracic lymph node $\mathrm{TB}^{20}$ ); pulmonary only (only lung parenchyma involved); pulmonary and extrapulmonary (pulmonary disease and one or more extrapulmonary sites involved concurrently); and lymph node disease only (intrathoracic or extrathoracic). For comparative analyses we excluded all patients with concurrent pulmonary-extrapulmonary disease, as others ${ }^{10} 1130$ have done, to minimise misclassification bias as the dominant disease site is unclear.

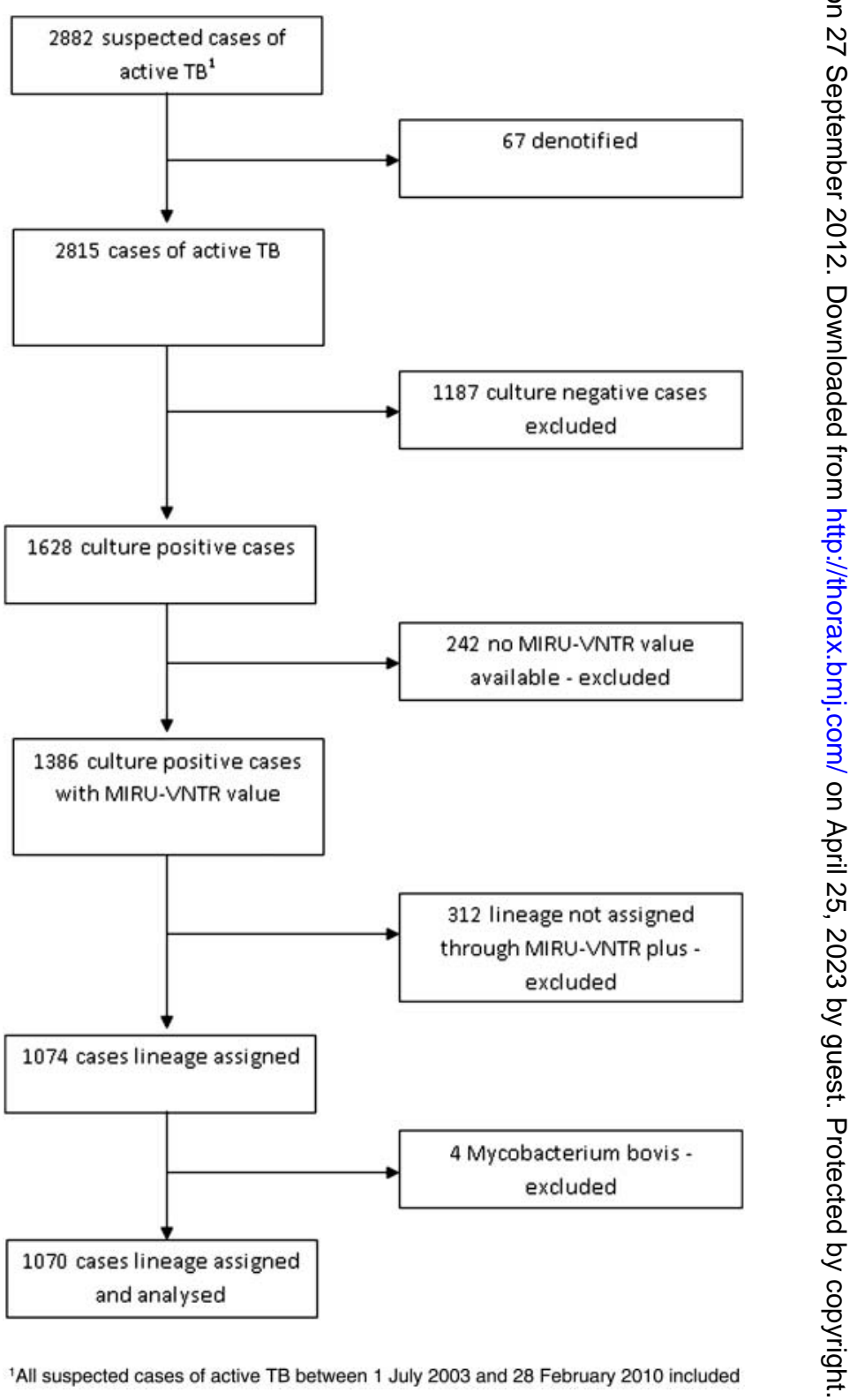

Figure 1 Flow chart of cases included in data analysis. 
Data analysis

Details of the data analysis are presented in the online supplementary information.

\section{RESULTS}

\section{Description of cohort}

The study flowchart is presented in figure 1 and demographic and clinical details of the cohort in table 1 . Median time between arrival in the UK and development of active TB was
5 years (IQR 2-21). Individuals with MIRU-VNTR values $(n=1070)$ were not significantly different, in terms of demographic and clinical features, to individuals without MIRU-VNTR values and to individuals with MIRU-VNTR values that could not be assigned to a lineage (table 1).

Distribution, and temporal trends, of lineages in cohort

In our cohort, Euro-American was the commonest lineage (43.7\%), followed by East African Indian (30.2\%),

Table 1 Demographic characteristics of individuals with active tuberculosis compared with those with no mycobacterial interspersed repetitive units containing variable numbers of tandem repeats (MIRU-VNTR) value and when no mycobacterial lineage could be assigned

\begin{tabular}{|c|c|c|c|c|c|}
\hline Variable & $\begin{array}{l}\text { Subjects included } \\
\text { in study }(n=1070)\end{array}$ & $\begin{array}{l}\text { Subjects with no } \\
\text { MIRU available }(n=242)\end{array}$ & p Value* & $\begin{array}{l}\text { Subjects with no lineage } \\
\text { assigned }(n=312)\end{array}$ & $\mathrm{p}$ Valuet \\
\hline \multicolumn{6}{|l|}{ Age } \\
\hline Median (IQR) & $34.8(25.0-49.7)$ & $36.2(24.0-49.6)$ & 0.11 & $32(25.3-52.2)$ & 0.42 \\
\hline \multicolumn{6}{|l|}{ Age categories } \\
\hline Under 16 & $36(3.4 \%)$ & $12(5.0 \%)$ & & $18(5.8 \%)$ & \\
\hline $16-25$ & $273(25.5 \%)$ & $54(22.3 \%)$ & & $66(21.2 \%)$ & \\
\hline $26-35$ & $261(24.4 \%)$ & $53(21.9 \%)$ & & $98(31.4 \%)$ & \\
\hline $36-45$ & $194(18.1 \%)$ & $36(14.9 \%)$ & & $34(10.9 \%)$ & \\
\hline $46-55$ & $96(9.0 \%)$ & $21(8.7 \%)$ & & $32(10.3 \%)$ & \\
\hline over 55 & $210(19.6 \%)$ & $66(27.3 \%)$ & & $64(20.5 \%)$ & \\
\hline \multicolumn{6}{|l|}{ Gender } \\
\hline Men & $579(54.1 \%)$ & 145 (59.9\%) & 0.12 & 159 (51.0\%) & 0.33 \\
\hline \multicolumn{6}{|l|}{ Ethnicity } \\
\hline White & $148(13.8 \%)$ & $30(12.4 \%)$ & 0.50 & $24(7.7 \%)$ & 0.024 \\
\hline Indian subcontinent & 577 (53.9\%) & $125(51.7 \%)$ & & 185 (59.3\%) & \\
\hline Afro-Caribbean & $278(26.0 \%)$ & $72(29.8 \%)$ & & $89(28.5 \%)$ & \\
\hline Oriental/other Asia & $23(2.2 \%)$ & $8(3.3 \%)$ & & $3(1.0 \%)$ & \\
\hline Other & $44(4.1 \%)$ & $7(2.9 \%)$ & & $11(3.5 \%)$ & \\
\hline \multicolumn{6}{|l|}{ Place of birth } \\
\hline Foreign born & $752(70.3 \%)$ & $181(74.8 \%)$ & 0.16 & $248(79.5 \%)$ & $0.001 \ddagger$ \\
\hline \multicolumn{6}{|l|}{ Time since entry to the UK (years) } \\
\hline Median (IQR) & $5(2-21) \S$ & $6(3-20)$ & 0.54 & $6(3-18)$ & 0.76 \\
\hline$<1$ & $24(3.4 \%)$ & $8(4.9 \%)$ & & $11(4.8 \%)$ & \\
\hline $1-5$ & $338(48.0 \%)$ & $72(44.2 \%)$ & & $95(41.1 \%)$ & \\
\hline $6-10$ & $95(13.5 \%)$ & $24(14.7 \%)$ & & $47(20.4 \%)$ & \\
\hline$>10$ & $247(35.1 \%)$ & $59(36.2 \%)$ & & $78(33.8 \%)$ & \\
\hline \multicolumn{6}{|l|}{ HIV status } \\
\hline Negative & $70(84.3 \%) \emptyset$ & $13(86.7 \%)$ & 0.82 & $23(95.8 \%)$ & 0.14 \\
\hline \multicolumn{6}{|l|}{ Previous TB } \\
\hline No & $1030(96.3 \%)$ & $228(94.2 \%)$ & 0.14 & 299 (95.8\%) & 0.72 \\
\hline \multicolumn{6}{|l|}{ Type of disease } \\
\hline Pulmonary only & $557(52.1 \%)$ & $115(47.5 \%)$ & 0.23 & $155(49.7 \%)$ & 0.48 \\
\hline Pulmonary and extrapulmonary & $118(11.0 \%)$ & $37(15.3 \%)$ & 0.08 & $40(12.8 \%)$ & 0.42 \\
\hline Extrapulmonary only & $395(36.9 \%)$ & $90(37.2 \%)$ & 0.94 & $117(37.5 \%)$ & 0.89 \\
\hline Extrathoracic only & $318(29.7 \%)$ & $73(30.2)$ & 0.88 & $96(30.8)$ & 0.73 \\
\hline Lymph node only & $204(19.1 \%)$ & $44(18.2)$ & 0.79 & $63(20.2)$ & 0.68 \\
\hline \multicolumn{6}{|l|}{ Smear result } \\
\hline Positive & $545(50.9 \%)$ & $108(44.6 \%)$ & & $150(48.1 \%)$ & 0.40 \\
\hline \multicolumn{6}{|l|}{ Drug sensitivity** } \\
\hline Fully sensitive & $976(95.2 \%)$ & $117(88.0 \%)$ & 0.007 & $288(96.6 \%)$ & 0.43 \\
\hline Mono-drug resistant & $37(3.6 \%)$ & $12(9.0 \%)$ & & $9(3.0 \%)$ & \\
\hline Multi-drug resistant & $12(1.2 \%)$ & $4(3.0 \%)$ & & $1(0.3 \%)$ & \\
\hline
\end{tabular}


Table 2 Distribution of Mycobacterium tuberculosis lineages by different world regions of birth*

\begin{tabular}{|c|c|c|c|c|c|}
\hline \multirow[b]{2}{*}{ World region of birth } & \multicolumn{5}{|l|}{ Lineage } \\
\hline & $\begin{array}{l}\text { East Asian } \\
(n=130)\end{array}$ & $\begin{array}{l}\text { Euro-Americant } \\
(n=459)\end{array}$ & $\begin{array}{l}\text { East African Indian } ¥ \\
(\mathrm{n}=321)\end{array}$ & $\begin{array}{l}\text { Indo-0ceanic } \\
(n=144)\end{array}$ & $\begin{array}{l}\text { West African } 1 / 2 \\
(n=4)\end{array}$ \\
\hline Americas and Caribbean & $0(0.0)$ & $14(87.5)$ & $2(12.5)$ & $0(0.0)$ & $0(0.0)$ \\
\hline Europe & $34(10.2)$ & $209(62.8)$ & $74(22.2)$ & $15(4.5)$ & $1(0.3)$ \\
\hline Middle East/North Africa & $0(0.0)$ & $11(84.6)$ & $1(7.69)$ & $1(7.7)$ & $0(0.0)$ \\
\hline South Africa & $4(8.7)$ & $36(78.3)$ & $0(0.0)$ & $6(13.0)$ & $0(0.0)$ \\
\hline West and Central Africa & $2(11.8)$ & $12(70.6)$ & $0(0.0)$ & $2(11.8)$ & $1(5.9)$ \\
\hline East Africa & $25(16.8)$ & $74(49.7)$ & $16(10.7)$ & $32(21.5)$ & $2(1.3)$ \\
\hline $\begin{array}{l}\text { Indian subcontinent and Central } \\
\text { Asia }\end{array}$ & $59(12.6)$ & $102(21.7)$ & $227(48.3)$ & $82(17.4)$ & $0(0.0)$ \\
\hline Southeast and East Asia & $6(42.9)$ & $1(7.1)$ & $1(7.1)$ & $6(42.9)$ & $0(0.0)$ \\
\hline
\end{tabular}

Indo-Oceanic (13.6\%) and Beijing (12.2\%). West African-1 $(0.0 \%)$ and West African-2 (0.7\%) lineages were rarely found in this cohort. The proportion of cases caused by any specific lineage in any given year did not change significantly over the course of the study period (see online supplementary figure S1).

\section{Distribution of lineages by geographical origin and ethnic group}

Table 2 and online supplementary figure S2 present the global distribution of lineages stratified by region, and country, of origin respectively. In general, lineages were geographically restricted and associated with specific regions. For example, the Euro-American lineage was predominantly found in Europe, the Americas and Africa, which together accounted for $74.7 \%$ of all cases caused by this lineage. East African Indian and Indo-Oceanic lineages were mainly found in the Indian subcontinent and East Africa (75.7\%) and Indian subcontinent, East Africa and Asia (83.3\%) respectively. By contrast, the East Asian strain appeared more geographically widespread, being found in the Indian subcontinent and East Africa and accounted for $55.6 \%$ of cases in the small number of individuals (nine) from East Asia.

Stratification of lineages by ethnic group (see online supplementary table S1) illustrated that, within specific regions, individuals of certain ethnicity were preferentially associated with particular lineages. Individuals of White (OR 4.56; 95\% CI 3.08 to 6.75 ) and Afro-Caribbean (OR 3.21; 95\% CI 2.42 to 4.28) ethnicity were significantly more likely to present with disease caused by the Euro-American lineage. By contrast, individuals in the Indian subcontinent group were significantly associated with the East African Indian (OR 5.89; 95\% CI 4.30 to 8.06 ) and Indo-Oceanic lineages (OR 1.69; 95\% CI 1.17 to 2.43 ) whereas the Oriental/Other Asia group was associated with the East Asian lineage (OR 3.29; 95\% CI 1.33 to 8.15 ).

Differences in lineage were also evident when comparing UK-born and foreign-born individuals of non-white ethnicity (see online supplementary table S1). The Euro-American lineage was significantly less common among foreign-born (compared with the UK-born) individuals of Indian subcontinent (OR 0.38 ; $95 \%$ CI 0.25 to 0.58 ) and Afro-Caribbean (OR $0.40 ; 95 \%$ CI 0.20 to 0.82 ) ethnicity.

\section{Association of time since arrival and development of active} TB for different lineages

Online supplementary figure S3 illustrates, for the foreign-born cohorts, the time between arrival in the UK and the development of active TB for the lineages in our cohort. Patients infected with the East African Indian lineage presented later (median 7 years, IQR 3-29) than the Euro-American lineage (median 5 years, IQR 2-18) $(\mathrm{p}=0.001)$.

\section{Demographic factors associated with mycobacterial lineage}

Table 3 depicts results of the univariate and multivariate analysis of the demographic and clinical factors associated with the four main lineages in our cohort (East Asian, Euro-American, East African Indian and Indo-Oceanic). On multivariate analysis, foreign birth and, in comparison to White ethnicity, certain non-white ethnic groups were inversely associated with Euro-American lineage (table 3). By contrast, Afro-Caribbean individuals were equally likely as White individuals to harbour the Euro-American lineage. Certain ethnic groups were either associated (Indian subcontinent) or inversely associated (Afro-Caribbean) with the East African Indian lineage. Foreign-birth and non-white ethnicity were significantly associated with the Indo-Oceanic lineage (table 3).

\section{Factors associated with disease patterns on univariate analysis}

Table 4 illustrates the clinical phenotypes of active TB (data for pulmonary only and extrathoracic disease only presented in table 4) stratified by lineage and ethnic group. In general, extrapulmonary only, extrathoracic only and lymph node only disease were more frequent in individuals who were foreign born $(\mathrm{p}<0.0001$ for all three) and of non-white ethnicity $(p<0.0001$ for all three). UK-born individuals of White ethnicity had a significantly lower proportion of extrapulmonary only $(7.7 \%)$, extrathoracic only $(2.4 \%)$ and lymph node only $(0.8 \%)$ disease compared with individuals of UK-born nonwhite ethnicity $(31.9 \%, 25.9 \%$ and $20.4 \%$ respectively) $(\mathrm{p}<0.0001$ for all three) and both these groups had significantly lower proportions of all three extrapulmonary phenotypes compared with individuals of foreign-born non-white ethnicity (51.1\%, 46.5\% and 35.4\%; $\mathrm{p}<0.0001$ for UK-born White and UK-born non-white). 
Table 3 Univariate and multivariate association of demographic, clinical and temporal factors with different Mycobacterium tuberculosis lineages

\begin{tabular}{|c|c|c|c|c|c|c|c|c|}
\hline Variable & East Asian $(n=130)$ & Adjusted ORT $(95 \% \mathrm{Cl})$ & Euro-American ( $n=468)$ & Adjusted OR‡ (95\% Cl) & East African Indian ( $n=323)$ & Adjusted OR‡ (95\% Cl) & Indo-Oceanic $(n=145)$ & Adjusted OR $¥(95 \% \mathrm{Cl}$ \\
\hline \multicolumn{9}{|l|}{ Period } \\
\hline 2003-2004 & 25/227 (11) & $1 \neq$ & 113/227 (49.8) & 1 & $64 / 227(28.2)$ & $1 \neq$ & 24/227 (10.6) & 1 \\
\hline 2005-2006 & 48/342 (14) & 1.27 (0.75 to 2.14$)$ & 133/342 (38.9) & 0.65 (0.44 to 0.96$)$ & 104/342 (30.4) & $1.08(0.72$ to 1.63$)$ & $55 / 342(16.1)$ & 1.47 (0.87 to 2.50$)$ \\
\hline 2007-2008 & $35 / 336(10.4)$ & 0.89 (0.51 to 1.57$)$ & $153 / 336(45.5)$ & 0.86 (0.58 to 1.26$)$ & 105/336 (31.3) & 1.18 (0.79 to 1.78$)$ & $42 / 336(12.5)$ & $1.14(0.65$ to 2.00$)$ \\
\hline 2009-2010 & $22 / 165(13.3)$ & 1.32 (0.69 to 2.50$)$ & 69/165 (41.8) & 0.71 (0.44 to 1.15$)$ & $50 / 165(30.3)$ & $1.03(0.63$ to 1.70$)$ & $24 / 165(14.5)$ & $1.46(0.76$ to 2.78$)$ \\
\hline \multicolumn{9}{|l|}{ Age categories n (\%) } \\
\hline Under 16 & $4 / 36(11.1)$ & 1 & 19/36 (52.8) & 1 & 9/36 (25) & 1 & 4/36 (11.1) & 1 \\
\hline $16-25$ & $32 / 273(11.7)$ & 0.88 (0.28 to 2.74$)$ & 128/273 (46.9) & 1.10 (0.50 to 2.44$)$ & $75 / 273(27.5)$ & $0.90(0.37$ to 2.20$)$ & $35 / 273(12.8)$ & 0.95 (0.30 to 2.96$)$ \\
\hline $26-35$ & $31 / 261(11.9)$ & $0.86(0.27$ to 2.75$)$ & 104/261 (39.8) & 1.01 (0.45 to 2.29$)$ & $82 / 261(31.4)$ & 0.90 (0.36 to 2.24$)$ & $43 / 261(16.5)$ & 1.09 (0.35 to 3.46$)$ \\
\hline $36-45$ & 31/194 (16) & $1.25(0.39$ to 4.03$)$ & 87/194 (44.8) & 0.88 (0.38 to 2.04$)$ & 46/194 (23.7) & 0.75 (0.29 to 1.93$)$ & 30/194 (15.5) & $1.28(0.39$ to 4.13$)$ \\
\hline $46-55$ & $11 / 96(11.5)$ & $0.73(0.20$ to 2.69$)$ & $40 / 96(41.7)$ & $1.19(0.47$ to 3.01$)$ & 29/96 (30.2) & 0.83 (0.30 to 2.28$)$ & $16 / 96(16.7)$ & $1.11(0.32$ to 3.87$)$ \\
\hline Over 55 & $21 / 210(10)$ & 0.71 (0.21 to 2.42 ) & $90 / 210(42.9)$ & 1.50 (0.63 to 3.56$)$ & $82 / 210(39)$ & 0.99 (0.38 to 2.54$)$ & $17 / 210(8.1)$ & 0.53 (0.15 to 1.82$)$ \\
\hline \multicolumn{9}{|l|}{ Gender } \\
\hline Men & $71 / 579(12.3)$ & 1 & 263/579 (45.4) & 1 & $162 / 579(28.0)$ & 1 & $81 / 579(14.0)$ & 1 \\
\hline Women & $59 / 491(12.0)$ & $0.94(0.64$ to 1.4$)$ & 205/491 (41.8) & 1.14 (0.85 to 1.52$)$ & 161/491 (32.8) & $0.99(0.73$ to 1.33$)$ & $64 / 491(13.0)$ & 0.85 (0.58 to 1.24$)$ \\
\hline \multicolumn{9}{|l|}{ Place of birth } \\
\hline UK & $30 / 318(9.4)$ & 1 & 200/318 (62.9) & $1^{*}$ & 72/318 (22.6) & 1 & $15 / 318(4.7)$ & $1^{* * *}$ \\
\hline Foreign born & 100/752 (13.3) & $1.52(0.84$ to 2.75$)$ & 268/752 (35.6) & $0.40(0.27$ to 0.60$)$ & 251/752 (33.4) & 1.34 (0.87 to 2.08$)$ & 130/752 (17.3) & 2.44 (1.31 to 4.53$)$ \\
\hline \multicolumn{9}{|l|}{ Ethnicity } \\
\hline White & 16/148 (10.8) & 1 & 110/148 (74.3) & $1^{*}$ & 21/148 (14.2) & $1^{*}$ & 1/148 (0.7) & $1^{* * * *}$ \\
\hline Indian subcontinent & 69/577 (12) & 0.79 (0.36 to 1.71$)$ & 151/577 (26.2) & $0.23(0.14$ to 0.39$)$ & 262/577 (45.4) & 4.04 (2.19 to 7.45$)$ & 94/577 (16.3) & $14.02(1.81$ to 108.52$)$ \\
\hline Afro-Caribbean & $35 / 278(12.6)$ & 0.77 (0.33 to 1.81$)$ & 180/278 (64.7) & 1.54 (0.85 to 2.82$)$ & 21/278 (7.6) & $0.38(0.18$ to 0.84$)$ & 39/278 (14) & 9.21 (1.15 to 73.58$)$ \\
\hline Oriental/other Asia & $7 / 23(30.4)$ & 2.63 (0.78 to 8.84$)$ & $4 / 23(17.4)$ & 0.12 (0.03 to 0.47$)$ & $6 / 23(26.1)$ & 1.78 (0.56 to 5.62$)$ & $6 / 23(26.1)$ & 21.99 (2.28 to 212.42$)$ \\
\hline Other & $3 / 44(6.8)$ & $0.43(0.10$ to 1.75$)$ & 23/44 (52.3) & 0.98 (0.43 to 2.23$)$ & $13 / 44(29.5)$ & $1.84(0.73$ to 4.66$)$ & $5 / 44(11.4)$ & $6.38(0.64$ to 63.52$)$ \\
\hline \multicolumn{9}{|l|}{ HIV status } \\
\hline Negative/unknown & 128/1057 (12.1) & 1 & 460/1057 (43.5) & 1 & $322 / 1057(30.5)$ & 1 & 143/1057 (13.5) & 1 \\
\hline Positive & 2/13 (15.4) & $1.21(0.25$ to 5.91$)$ & $8 / 13(61.5)$ & 1.06 (0.31 to 3.61$)$ & $1 / 13(7.7)$ & 0.78 (0.09 to 6.90$)$ & $2 / 13(15.4)$ & 0.97 (0.20 to 4.69$)$ \\
\hline \multicolumn{9}{|l|}{ Previous TB } \\
\hline No & 130/1030 (12.6) & & 447/1030 (43.4) & 1 & $306 / 1030(29.7)$ & $1 * *$ & 143/1030 (13.9) & 1 \\
\hline Yes & $0 / 40(0.0)$ & & $21 / 40(52.5)$ & 1.35 (0.66 to 2.76$)$ & $17 / 40(42.5)$ & 2.07 (1.00 to 4.31$)$ & $2 / 40(5.0)$ & 0.37 (0.09 to 1.58$)$ \\
\hline \multicolumn{9}{|l|}{ Drug sensitivity } \\
\hline Fully sensitive & 119/976 (12.2) & 1 & 431/976 (44.2) & 1 & 293/976 (30.0) & 1 & 130/976 (13.3) & 1 \\
\hline Drug resistant§ & $7 / 49(14.3)$ & 1.21 (0.52 to 2.83 ) & $15 / 49$ (30.6) & 0.65 (0.33 to 1.29$)$ & $17 / 49(34.7)$ & 1.07 (0.55 to 2.07$)$ & 9/49 (18.4) & 1.27 (0.58 to 2.78$)$ \\
\hline \multicolumn{9}{|c|}{ Duration of symptoms before treatment } \\
\hline $0-15$ days & $5 / 59(8.5)$ & & 29/59 (49.2) & & $18 / 59(30.5)$ & & $7 / 59(11.9)$ & \\
\hline $16-30$ days & $6 / 56(10.7)$ & & 25/56 (44.6) & & $17 / 56(30.4)$ & & $8 / 56(14.3)$ & \\
\hline $31-45$ days & $7 / 61$ (11.5) & & 25/61 (41) & & 21/61 (34.4) & & $8 / 61$ (13.1) & \\
\hline $46-60$ days & $5 / 43(11.6)$ & & $20 / 43(46.5)$ & & 10/43 (23.3) & & $8 / 43(18.6)$ & \\
\hline 61 days and over & $31 / 243(12.8)$ & & 99/243 (40.7) & & $83 / 243(34.2)$ & & $30 / 243(12.3)$ & \\
\hline \multicolumn{9}{|l|}{ Smear positive } \\
\hline No & 74/525 (14.1) & 1 & 211/525 (40.2) & 1 & 162/525 (30.9) & 1 & 76/525 (14.5) & 1 \\
\hline Yes & $56 / 545(10.3)$ & 0.73 (0.49 to 1.08$)$ & $257 / 545(47.2)$ & 0.98 (0.74 to 1.31$)$ & 161/545 (29.5) & $1.18(0.88$ to 1.59$)$ & 69/545 (12.7) & 1.04 (0.71 to 1.53$)$ \\
\hline
\end{tabular}

${ }^{*} \mathrm{p}<0.0001 ;{ }^{* *} \mathrm{p}=0.05 ;{ }^{* * *} \mathrm{p}=0.005 ;{ }^{* * * *} \mathrm{p}=0.015$

†Model mutually adjusted for year of notification, age, gender, ethnicity, country of birth. HIV status, drug sensitivity and smear positivity; data analysed using logistic regression.

$\ddagger$ Model mutually adjusted for year of notification, age, gender, ethnicity, country of birth, HIV status, previous TB, drug sensitivity and smear positivity; data analysed using logistic regression.

fModel mutually adjusted for year of notification, age, gender, ethnicity, country of birth, HIV stats,
§Drug-resistant category includes individuals with mono-resistant TB and multi-drug resistant TB.

§Drug-resistant cate
TB, tuberculosis.

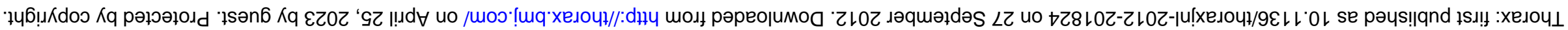


Table 4 Different clinical phenotypes of active tuberculosis stratified by lineage and demographic group

\begin{tabular}{|c|c|c|c|c|c|c|c|c|c|}
\hline \multirow[b]{3}{*}{$\begin{array}{l}\text { Mycobacterial } \\
\text { lineage }\end{array}$} & \multicolumn{9}{|c|}{ Clinical phenotype and demographic group } \\
\hline & \multicolumn{4}{|c|}{ Pulmonary only $(n=545)^{*}$} & \multicolumn{5}{|c|}{ Extrathoracic only $(n=317)$ * } \\
\hline & $\begin{array}{l}\text { UK born } \\
\text { white }\end{array}$ & $\begin{array}{l}\text { UK born } \\
\text { non-white }\end{array}$ & $\begin{array}{l}\text { Foreign born } \\
\text { non-white }\end{array}$ & Totaltף & $\begin{array}{l}\text { UK born } \\
\text { white }\end{array}$ & $\begin{array}{l}\text { UK born } \\
\text { non-white }\end{array}$ & $\begin{array}{l}\text { Foreign born } \\
\text { non-white }\end{array}$ & Total‡ף & $\begin{array}{l}\mathrm{p} \\
\text { Value§ף }\end{array}$ \\
\hline East Asian & $12(100.0)$ & $5(62.5)$ & $34(43.0)$ & 51 & $0(0.0)$ & $3(37.5)$ & $45(57.0)$ & 48 & $<0.0001$ \\
\hline Euro-American & $88(97.8)$ & $62(77.5)$ & $118(58.7)$ & 268 & $2(2.2)$ & $18(22.5)$ & $83(41.3)$ & 103 & $<0.0001$ \\
\hline East African Indian & $19(95.0)$ & $33(73.3)$ & $118(58.1)$ & 170 & $1(5.0)$ & $12(26.7)$ & $85(41.9)$ & 98 & 1.00 \\
\hline Indo-Oceanic & $1(100.0)$ & $8(61.5)$ & $47(41.9)$ & 56 & $0(0.0)$ & $5(38.5)$ & $63(57.3)$ & 68 & $<0.0001$ \\
\hline \multicolumn{10}{|c|}{$\begin{array}{l}\text { *The figures presented in each column refer to the number of cases and percentage. Percentages of cases that were pulmonary only and extrathoracic only are calculated for each } \\
\text { lineage and demographic group separately. Data for extrapulmonary TB and lymph node TB not shown but results are essentially the same as those shown in table } 4 \text { for extrathoracic } \\
\text { TB disease. } \\
\text { †Total refers to the total number of cases that were pulmonary only for each lineage (ie should be read across). } \\
\text { †Total refers to the total number of case that were extrathoracic only for each lineage (ie should be read across). } \\
\text { \$p Value refers to the comparison between the three demographic groups (UK-born white versus UK-born non-white versus foreign-born non-white) of the proportion of cases that are } \\
\text { extrathoracic only for each lineage in turn; data analysed using Fisher's exact test. } \\
\text { IFor the total cohort the East Asian }(51 / 545,9.4 \% \text { vs } 48 / 317,15.1 \% ; p=0.014) \text { and Indo-Oceanic lineages }(51 / 545,9.4 \% \text { vs } 48 / 317,15.1 \% ; p=0.014) \text { were significantly more likely to } \\
\text { cause extrathoracic only disease compared with pulmonary only disease whereas the Euro-American lineage was significantly more likely to cause pulmonary only disease than } \\
\text { extrathoracic only disease }(268 / 545,49.2 \% \text { vs } 103 / 317,32.5 \% ; p<0.0001) ; \text { data analysed using Fisher's exact test. } \\
\text { TB, tuberculosis. }\end{array}$} \\
\hline
\end{tabular}

East Asian and Indo-Oceanic lineages were significantly more likely to cause extrapulmonary only, extrathoracic only and lymph node only disease compared with pulmonary only disease (table 4). By contrast, the Euro-American lineage was significantly more likely to cause pulmonary disease and was inversely associated with extrapulmonary only, extrathoracic only and lymph node only disease (table 4).

\section{Factors associated with disease patterns on multivariate analysis}

Multivariate associations of factors associated with extrathoracic disease are presented in table 5. Certain lineages (with East Asian as the referent category) were negatively associated with extrathoracic only disease (East African Indian and Euro-American). With Euro-American lineage (the most frequent lineage in this cohort) as the reference category, the East Asian lineage (OR 1.86; 95\% CI 1.10 to 3.15) was positively associated with extrathoracic disease but the East African Indian lineage was not (OR $0.94 ; 95 \%$ CI 0.62 to 1.42) (data not shown).

However, ethnicity was most strongly associated with clinical phenotype with Afro-Caribbean and Indian subcontinent ethnicities conferring adjusted ORs of 14 to 21, respectively, for extrathoracic disease.

Additional factors independently associated with the different extrapulmonary phenotypes were increasing age, female gender, foreign birth and time since UK entry (table 5).

\section{DISCUSSION}

TB can present as a disease spectrum usually involving the lungs but not uncommonly purely extrapulmonary or extrathoracic sites. Although these clinical disease patterns must represent the end result of an interaction between host, environment and mycobacterial lineage the relative importance of these three factors is unknown and can only be dissected in an ethnically heterogeneous population with detailed demographic, clinical and strain typing data, as presented here.

We found that $M t b$ lineages mapped with patients' geographical origins and were associated with distinct ethnic groups, as previously described. ${ }^{2-5}$ After adjustment for demographics, certain lineages, such as Euro-American and East African Indian, were significantly less likely to cause extrapulmonary TB whereas others, such as East Asian, were associated with extrapulmonary disease. However, ethnicity was the factor most strongly associated with clinical phenotype. This was exemplified by the large population of Indian subcontinent ethnicity who, as previously described, ${ }^{2}{ }^{3}$ harboured predominantly the East African Indian lineage which was preferentially associated with pulmonary disease; however, ethnicity overrode this association resulting in a predominantly extrathoracic and extrapulmonary pattern of disease. Indeed, with mutual multivariate adjustment, ethnicity in this ethnically diverse UK setting was more strongly associated with clinical phenotype than $M t b$ lineage, suggesting that the host is a relatively more powerful determinant of disease phenotype than mycobacterial lineage. Although non-white ethnicity has previously been recognised to be associated with extrapulmonary disease, the impact of $M t b$ lineage was not taken into account. Interpretation of such associations has therefore been difficult, given the association of different lineages with different ethnic groups and patients' geographical origins.

Only Click and colleagues, in the USA, assessed the association between $M t b$ lineage and disease phenotype taking ethnicity and geographical origins into account. ${ }^{20}$ They found that while lineage was clearly associated with disease phenotype only weak associations with ethnicity were observed. ${ }^{20}$ The reason for the weaker influence of ethnicity compared with our study is unclear but may lie in differences in the ethnicities of non-white ethnic groups in the USA compared with the UK. Specifically, Indian subcontinent ethnicity was not included as an ethnic grouping in the US study whereas in our study it was the largest subgroup and the most strongly associated with extrathoracic disease. This strong association of Indian subcontinent ethnicity with extrathoracic disease, independently of lineage, has broad epidemiological relevance because not only is this ethnic group the most important in terms of national TB burden in the UK, ${ }^{31}$ but it also accounts for more than a quarter of TB cases globally. ${ }^{1}$ Although our findings highlight that the host is dominant in shaping clinical disease phenotype, we cannot currently distinguish whether the key determinant is the host per se (ie, host genotype) or whether ethnicity serves as a proxy for another host-related factor. ${ }^{32}$

Previous studies of different lineages with clinical disease pattern have generated conflicting results. Associations identified 
Table 5 Univariate and multivariate association of demographic, clinical and temporal factors with extrathoracic tuberculosis for four main lineages (excluding West African-1 and 2)

\begin{tabular}{|c|c|c|c|c|}
\hline Variable & Extrathoracic TB only* $(n=318)$ & Unadjusted OR $(95 \% \mathrm{Cl})$ & Adjusted ORt $(95 \% \mathrm{Cl})$ & $p$ Value \\
\hline \multicolumn{5}{|l|}{ Period } \\
\hline 2003-2004 & $54 / 192(28.1)$ & 1 & 1 & \multirow[t]{4}{*}{0.53} \\
\hline 2005-2006 & $114 / 280(40.7)$ & $1.76(1.18$ to 2.60$)$ & 1.39 (0.89 to 2.17$)$ & \\
\hline 2007-2008 & $100 / 269(37.2)$ & 1.51 (1.01 to 2.26$)$ & 1.21 (0.77 to 1.92$)$ & \\
\hline 2009-2010 & 50/134 (37.3) & 1.52 (0.95 to 2.44$)$ & $1.16(0.67$ to 2.00$)$ & \\
\hline \multicolumn{5}{|l|}{ Age categories $\mathrm{n}(\%)$} \\
\hline Under 16 & 9/27 (33.3) & 1 & 1 & \multirow[t]{6}{*}{0.005} \\
\hline $16-25$ & 69/234 (29.5) & $0.84(0.36$ to 1.95$)$ & $0.72(0.29$ to 1.80$)$ & \\
\hline $26-35$ & $88 / 208(42.3)$ & 1.47 (0.63 to 3.42$)$ & 1.10 (0.43 to 2.82 ) & \\
\hline $36-45$ & 71/163 (43.6) & 1.54 (0.65 to 3.64$)$ & 1.74 (0.66 to 4.59$)$ & \\
\hline $46-55$ & $33 / 75$ (44) & 1.57 (0.63 to 3.95$)$ & 1.91 (0.64 to 5.65$)$ & \\
\hline Over 55 & 48/168 (28.6) & $0.80(0.34$ to 1.90$)$ & 0.87 (0.32 to 2.42 ) & \\
\hline \multicolumn{5}{|l|}{ Gender } \\
\hline Men & 147/461 (31.9) & 1 & 1 & \multirow[t]{2}{*}{0.016} \\
\hline Women & $171 / 414(41.3)$ & 1.50 (1.14 to 1.98$)$ & 1.49 (1.08 to 2.06$)$ & \\
\hline \multicolumn{5}{|l|}{ Country of birth/time since entry } \\
\hline UK born & $41 / 270(15.2)$ & 1 & 1 & \multirow[t]{6}{*}{0.0018} \\
\hline Foreign born $/<1$ year & $5 / 20(25)$ & $1.86(0.64$ to 5.40$)$ & 0.74 (0.22 to 2.58$)$ & \\
\hline Foreign born/ $1-5$ years & $130 / 278(46.8)$ & 4.91 (3.26 to 7.37 ) & 2.26 (1.38 to 3.69$)$ & \\
\hline Foreign born/ $6-10$ years & $42 / 75(56)$ & 7.11 (4.04 to 12.5$)$ & 3.08 (1.60 to 5.92$)$ & \\
\hline Foreign born $/>10$ years & $82 / 195(42.1)$ & 4.05 (2.62 to 6.28$)$ & 1.37 (0.75 to 2.51$)$ & \\
\hline Foreign born/time not known & 18/37 (48.6) & 5.29 (2.56 to 10.93$)$ & 2.28 (1.00 to 5.22$)$ & \\
\hline \multicolumn{5}{|l|}{ Ethnicity } \\
\hline White & $3 / 132(2.3)$ & 1 & 1 & \multirow[t]{5}{*}{$<0.0001$} \\
\hline Indian subcontinent & 206/466 (44.2) & 34.07 (10.69 to 108.59 ) & 21.14 (6.08 to 73.48$)$ & \\
\hline Afro-Caribbean & 88/222 (39.6) & 28.24 (8.71 to 91.52 ) & 14.05 (3.97 to 49.65$)$ & \\
\hline Oriental/other Asia & $4 / 20(20)$ & 10.75 (2.20 to 52.43$)$ & 4.56 (0.82 to 25.27$)$ & \\
\hline Other & $17 / 35(48.6)$ & 40.61 (10.82 to 152.44$)$ & 23.62 (5.68 to 98.17$)$ & \\
\hline \multicolumn{5}{|l|}{ Lineage } \\
\hline East Asian & $48 / 100(48)$ & 1 & 1 & \multirow[t]{4}{*}{0.01} \\
\hline Euro-American & 103/378 (27.2) & $0.41(0.26$ to 0.64$)$ & 0.54 (0.32 to 0.91$)$ & \\
\hline East African Indian & 98/269 (36.4) & $0.62(0.39$ to 0.99$)$ & 0.50 (0.29 to 0.86$)$ & \\
\hline Indo-Oceanic & 68/124 (54.8) & 1.32 (0.78 to 2.23$)$ & 0.91 (0.51 to 1.63$)$ & \\
\hline \multicolumn{5}{|l|}{ Employment status } \\
\hline Unemployed & $34 / 98(34.7)$ & 1 & & \\
\hline Retired & $12 / 54(22.2)$ & $0.54(0.25$ to 1.16$)$ & & \\
\hline Employed/housewife & $140 / 324(43.2)$ & $1.43(0.89$ to 2.29$)$ & & \\
\hline Student/child & $24 / 85(28.2)$ & 0.74 (0.39 to 1.39$)$ & & \\
\hline \multicolumn{5}{|l|}{ HIV status } \\
\hline Negative/unknown & $314 / 867(36.2)$ & 1 & 1 & \multirow[t]{2}{*}{0.88} \\
\hline Positive & $4 / 8(50.0)$ & $1.76(0.44$ to 7.09$)$ & $0.9(0.21$ to 3.84$)$ & \\
\hline \multicolumn{5}{|l|}{ Previous TB } \\
\hline No & 308/841 (36.6) & 1 & 1 & \multirow[t]{2}{*}{0.79} \\
\hline Yes & 10/34 (29.4) & $0.72(0.34$ to 1.53$)$ & 0.89 (0.39 to 2.04$)$ & \\
\hline \multicolumn{5}{|l|}{ Drug sensitivity } \\
\hline Fully sensitive & $288 / 800(36.0)$ & 1 & 1 & \multirow[t]{2}{*}{0.95} \\
\hline Drug-resistant $\ddagger$ & $16 / 41(39.0)$ & 1.14 (0.60 to 2.17 ) & 1.02 (0.5 to 2.1$)$ & \\
\hline
\end{tabular}

in a given ethnically homogeneous population have frequently not been replicable in other populations while studies in ethnically heterogeneous populations have hitherto failed to control for ethnicity, with the exception of Click et al. ${ }^{20}$

We found that the Euro-American and East African Indian lineages were associated with pulmonary disease whereas Click and colleagues found these lineages were associated with extrapulmonary disease. ${ }^{20}$ Previous authors have come to conflicting conclusions about the phenotypic associations of the Euro-American $^{19} 33$ and East African Indian lineages. ${ }^{19}$ 21-23 With the Euro-American lineage as the reference, we found the East Asian lineage was significantly associated, on multivariate 
analysis, with extrapulmonary disease. The mechanism underlying this propensity to disseminate is not known but may involve the ability of the Beijing (East Asian) lineage to produce a bioactive phenolic glycolipid which inhibits the innate immune system. ${ }^{33-35}$ As with other lineages, earlier studies have come to conflicting conclusions about the phenotypic association of the East Asian lineage. ${ }^{14-21}$

The predominant lineages in our study were geographically associated (table 2): Euro-American with Europe/Americas/ Africa, East African Indian with the Indian subcontinent/East Africa, Indo-Oceanic with the Indian subcontinent/East Africa/ Asia and East Asian with the Indian subcontinent/East Africa/ Asia. Our findings are in line with previous studies, ${ }^{2} \quad 3 \quad 5$ although the high proportion of individuals in our cohort from the Indian subcontinent, compared with the small proportion from East, and Southeast, Asia may have masked the association of these latter regions with the Indo-Oceanic and East Asian lineages. ${ }^{4} 5$

Lineages were also associated with distinct ethnic groups, with the Euro-American lineage associated with White and Afro-Caribbean individuals, East African Indian and Indo-Oceanic with Indian subcontinent ethnicity and East Asian with Oriental and Other Asia ethnicity. These findings are consistent with those of Evans et $a l^{4}$ who assigned ethnicity by name and Gagneux et $a l^{2}$ who found that US-born individuals of non-white ethnicity (mainly Chinese and Filipino) had the same lineages as individuals born in China and the Philippines. These close associations of lineages with self-reported ethnicity, an accurate marker of ancestry, ${ }^{36}$ are consistent with coevolution of mycobacteria and their human hosts. Alternatively, these associations could reflect infection with similar lineages following transmission within ethnic communities in the host countries through assortative mixing, after travel to countries of origin or visits from family based overseas. ${ }^{37}$

Our study had several limitations. One of these was lineage assignment. Although we used 15 loci MIRU-VNTR (the standard DNA fingerprinting method at the time) an online database (MIRU-VNTRplus) and published literature to assign lineages to isolates, a proportion could not be definitively classified into any of the six major lineages either due to the lower resolution of 15-MIRU-VNTR or because the online database did not contain data on enough lineages. However, the demographic and clinical profile of these individuals did not differ from the cohort that was analysed; sensitivity analyses including the non-lineage-assigned isolates did not provide any evidence that these isolates formed a distinct lineage with a separate clinical phenotype. In addition, the 15-MIRU-VNTR method was recently effectively used for lineage assignment by Click et al. ${ }^{20}$ An improved version of 15-MIRU-VNTR typing has subsequently been described that analyses 24-loci and provides greater resolution; an alternative would be to base lineage assignment on large sequence polymorphisms or whole-genome sequencing.

Although national guidelines now state that patients with TB should be tested for HIV, ${ }^{38}$ this was inconsistently recorded in our dataset as in many national surveillance systems. ${ }^{10} \quad \begin{array}{lll}11 & 21 & 39\end{array}$ While untreated HIV infection is well recognised to be an important factor in determining an extrapulmonary clinical phenotype ${ }^{40}$ its influence on clinical phenotype in our predominantly Indian subcontinent study population is probably very small as TB-HIV coinfection in this segment of the UK population is very low. ${ }^{41}$ Moreover, there is no association between HIV and clinical disease pattern in the post-antiretroviral therapy era. ${ }^{12}$ Other factors which may affect clinical presentation include age, iatrogenic immunosuppression and diabetes mellitus. ${ }^{42-44}$ To ensure unambiguous clinical phenotypes for our regression analyses, we classified cases as exclusively pulmonary and exclusively extrathoracic; the resulting exclusion of individuals with concurrent disease might therefore have resulted in some associations being missed. Future work should explore the factors (including ethnicity) that are associated with different extrathoracic disease subtypes. Whilst our study focused primarily on host factors and mycobacterial lineage, an alternative area of potential relevance, and future study, is the impact of environment on clinical phenotype with, for example, the recency of $M t b$ transmission potentially playing a role in determining clinical phenotype.

In conclusion, although $M t b$ lineages, which are geo-ethnically restricted, can be associated with specific clinical phenotypes, host ethnicity appears to be more important in determining the clinical pattern of tuberculous disease, at least in the case of Indian subcontinent ethnicity and extrathoracic and extrapulmonary disease. Future work should integrate host demographic and genotypic data with environmental data for factors associated with TB, such as smoking and vitamin D levels.

Acknowledgements This publication made use of the MIRU-VNTRplus database website (http://www.miru-vntrplus.org/) developed by D Harmsen, S Nieman, P Supply and T Weniger.

Contributors AL, MP, Jl and GS conceived of the idea for the study; J: collected the clinical data as part of routine care; JE, EGS, PH: undertook the MIRU-VNTR typing and maintained the genotyping database; MP: undertook the data analysis; MP, AL: wrote the first draft of the manuscript with subsequent revisions made by all other coauthors. All coauthors had sight of the submitted paper. AL: guarantor for the paper.

Competing interests $\mathrm{AL}$ is inventor for patents underpinning T-cell-based diagnosis. The ESAT-6/CFP-10 ELISpot was commercialised by an Oxford University spin-out company (Oxford Immunotec Ltd, Abingdon, UK) in which Oxford University and Professor Lalvani have a minority share of equity. MP, JE, JI, EGS, SHW, KL, SS, $M D, P H$ have no conflict of interest.

Funding MP is currently a NIHR Academic Clinical Lecturer in Infectious Diseases; his PhD was funded by a Medical Research Council Capacity Building Studentship. AL is a Wellcome Senior Research Fellow in Clinical Science and NIHR Senior Investigator.

Ethicas approval No patient-specific data or personal identifiers were used in the preparation of this report which was an analysis of routine data collected as part of service evaluation.

Provenance and peer review Not commissioned; externally peer reviewed.

\section{REFERENCES}

1 World Health Organisation. Global tuberculosis control. Geneva: WHO, 2011.

2 Gagneux S, DeRiemer K, Van T, et al. Variable host-pathogen compatibility in Mycobacterium tuberculosis. Proc Natl Acad Sci U S A 2006;103:2869-73.

3 Reed MB, Pichler VK, McIntosh F, et al. Major Mycobacterium tuberculosis lineages associate with patient country of origin. J Clin Microbiol 2009;47:1119-28.

4 Evans JT, Gardiner S, Smith EG, et al. Global origin of Mycobacterium tuberculosis in the Midlands, UK. Emerg Infect Dis 2010;16:542-5.

5 Brown T, Nikolayevskyy V, Velji P, et al. Associations between Mycobacterium tuberculosis strains and phenotypes. Emerg Infect Dis 2010;16:272-80.

6 Coscolla M, Gagneux S. Does M. tuberculosis genomic diversity explain disease diversity? Drug Discov Today Dis Mech 2010;7:e43-59.

7 Portevin D, Gagneux S, Comas I, et al. Human macrophage responses to clinical isolates from the Mycobacterium tuberculosis complex discriminate between ancient and modern lineages. PLoS Pathog 2011 7:e1001307.

8 Wang $C$, Peyron $\mathrm{P}$, Mestre 0 , et al. Innate immune response to Mycobacterium tuberculosis Beijing and other genotypes. PLOS ONE 2010;5:e13594.

9 Li Q, Whalen CC, Albert JM, et al. Differences in rate and variability of intracellular growth of a panel of Mycobacterium tuberculosis clinical isolates within a human monocyte model. Infect Immun 2002;70:6489-93.

10 Peto HM, Pratt RH, Harrington TA, et al. Epidemiology of extrapulmonary tuberculosis in the United States, 1993-2006. Clin Infect Dis 2009;49: 1350-57.

11 te Beek LA, van der Werf MJ, Richter $C$, et al. Extrapulmonary tuberculosis by nationality, The Netherlands, 1993-2001. Emerg Infect Dis 2006:12:1375-82. 
12 Kruijshaar ME, Abubakar I. Increase in extrapulmonary tuberculosis in England and Wales 1999-2006. Thorax 2009;64:1090-95.

13 Thwaites G, Caws M, Chau TTH, et al. The relationship between Mycobacterium tuberculosis genotype and the clinical phenotype of pulmonary and meningeal tuberculosis. J Clin Microbiol 2008;46:1363-8.

14 Kong Y, Cave MD, Zhang L, et al. Association between Mycobacterium tuberculosis Beijing/W lineage strain infection and extrathoracic tuberculosis: insights from epidemiologic and clinical characterization of the three principal genetic groups of M. tuberculosis clinical isolates. J Clin Microbiol 2007;45:409-14.

15 Kong Y, Cave MD, Yang D, et al. Distribution of insertion- and deletion-associated genetic polymorphisms among four Mycobacterium tuberculosis phospholipase C genes and associations with extrathoracic tuberculosis: a population-based study. J Clin Microbiol 2005;43:6048-53.

16 Hesseling AC, Marais BJ, Kirchner HL, et al. Mycobacterial genotype is associated with disease phenotype in children. Int J Tuberc Lung Dis 2010;14:1252-58.

17 Nicol MP, Sola C, February B, et al. Distribution of strain families of Mycobacterium tuberculosis causing pulmonary and extrapulmonary disease in hospitalized children in Cape Town, South Africa. J Clin Microbiol 2005;43:5779-81.

18 Borgdorff MW, van Deutekom $\mathrm{H}$, de Haas PEW, et al. Mycobacterium tuberculosis, Beijing genotype strains not associated with radiological presentation of pulmonary tuberculosis. Tuberculosis (Edinb) 2004;84:337-40.

19 Lari N, Rindi L, Cristofani R, et al. Association of Mycobacterium tuberculosis complex isolates of Bovis and Central Asian (CAS) genotypic lineages with extrapulmonary disease. Clin Microbiol Infect 2009;15:538-43.

20 Click ES, Moonan PK, Winston CA, et al. Relationship between Mycobacterium tuberculosis phylogenetic lineage and clinical site of tuberculosis. Clin Infect Dis 2012;54:211-19.

21 Svensson E, Millet J, Lindqvist $A$, et al. Impact of immigration on tuberculosis epidemiology in a low-incidence country. Clin Microbiol Infect 2011;17:881-7.

22 Hasan Z, Tanveer M, Kanji A, et al. Spoligotyping of Mycobacterium tuberculosis isolates from Pakistan reveals predominance of Central Asian Strain 1 and Beijing isolates. J Clin Microbiol 2006;44:1763-68.

23 Tanveer M, Hasan Z, Siddiqui A, et al. Genotyping and drug resistance patterns of M. tuberculosis strains in Pakistan. BMC Infect Dis 2008:8:171.

24 Office for National Statistics. Annual Population Survey: Population by country of birth and nationality October 2009 to September 2010. London: Office for National Statistics, 2010

25 Health Protection Agency. Three-year Average Tuberculosis Case Reports and Rates by Primary Care Trust, England, 2006-2008. London: Health Protection Agency, 2009.

26 Evans JT, Hawkey PM, Smith EG, et al. Automated high-throughput mycobacterial interspersed repetitive unit typing of Mycobacterium tuberculosis strains by a combination of PCR and nondenaturing high-performance liquid chromatography. J Clin Microbiol 2004;42:4175-80.

27 Supply P, Allix C, Lesjean S, et al. Proposal for standardization of optimized mycobacterial interspersed repetitive unit-variable-number tandem repeat typing of Mycobacterium tuberculosis. J Clin Microbiol 2006;44:4498-510.
28 Allix-Beguec C, Harmsen D, Weniger T, et al. Evaluation and strategy for use of MIRU-VNTRplus, a multifunctional database for online analysis of genotyping data and phylogenetic identification of Mycobacterium tuberculosis complex isolates. J Clin Microbiol 2008;46:2692-99.

29 Office of National Statistics. Ethnic Group Statistics: A Guide for the Collection and Classification of Ethnicity Data. London: ONS, 2009.

30 García-Rodríguez JF, Álvarez-Díaz H, Lorenzo-García MV, et al. Extrapulmonary tuberculosis: epidemiology and risk factors. Enferm Infecc Microbiol Clin 2011;29:502-9.

31 Health Protection Agency. Tuberculosis in the UK: Annual Report on Tuberculosis Surveillance and Control in the UK 2010. London: Health Protection Agency Centre for Infections, 2010.

32 Wilkinson RJ, Llewelyn $M$, Toossi Z, et al. Influence of vitamin D deficiency and vitamin $\mathrm{D}$ receptor polymorphisms on tuberculosis among Gujarati Asians in west London: a case-control study. Lancet 2000;355:618-21.

33 Caws $M$, Thwaites $G$, Dunstan S, et al. The influence of host and bacterial genotype on the development of disseminated disease with Mycobacterium tuberculosis. PLoS Pathog 2008;4:e1000034.

34 Reed MB, Domenech P, Manca C, et al. A glycolipid of hypervirulent tuberculosis strains that inhibits the innate immune response. Nature 2004;431:84-7.

35 Tsenova L, Ellison E, Harbacheuski R, et al. Virulence of selected Mycobacterium tuberculosis clinical isolates in the rabbit model of meningitis is dependent on phenolic glycolipid produced by the bacilli. J Infect Dis 2005;192:98-106.

36 Rosenberg NA, Pritchard JK, Weber JL, et al. Genetic structure of human populations. Science 2002;298:2381-85.

37 Cobelens FGJ, van Deutekom H, Draayer-Jansen IWE, et al. Risk of infection with Mycobacterium tuberculosis in travellers to areas of high tuberculosis endemicity. Lancet 2000;356:461-65.

38 National Collaborating Centre for Chronic Conditions. Tuberculosis: Clinical Diagnosis and Management of Tuberculosis, and Measures for its Prevention and Control. London: Royal College of Physicians, 2011.

39 Rodger AJ, Story A, Fox Z, et al. HIV prevalence and testing practices among tuberculosis cases in London: a missed opportunity for HIV diagnosis? Thorax 2010;65:63-9.

40 Yang Z, Kong Y, Wilson F, et al. Identification of risk factors for extrapulmonary tuberculosis. Clin Infect Dis 2004;38:199-205.

41 Ahmed AB, Abubakar I, Delpech V, et al. The growing impact of HIV infection on the epidemiology of tuberculosis in England and Wales: 1999-2003. Thorax 2007:62:672-76

42 Ong A, Creasman J, Hopewell PC, et al. A molecular epidemiological assessment of extrapulmonary tuberculosis in San Francisco. Clin Infect Dis 2004;38:25-31.

43 Keane J, Gershon S, Wise RP, et al. Tuberculosis associated with infliximab, a tumor necrosis factor $\alpha$-neutralizing agent. N Eng/ J Med 2001;345:1098-104.

44 Dooley KE, Chaisson RE. Tuberculosis and diabetes mellitus: convergence of two epidemics. Lancet Infect Dis 2009;9:737-46. 